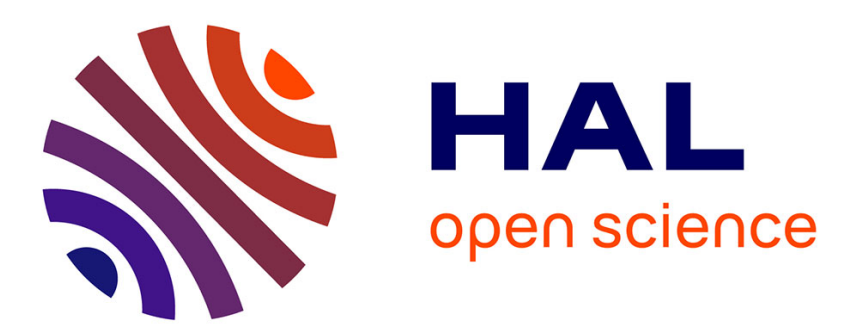

\title{
Analytical Computation of Flux Concentration PM Machines: Study of the Influence of the Magnets Shape
}

Lamia Belguerras, Larbi Hadjout, Thierry Lubin, Smail Mezani, Abderrezak Rezzoug

\section{- To cite this version:}

Lamia Belguerras, Larbi Hadjout, Thierry Lubin, Smail Mezani, Abderrezak Rezzoug. Analytical Computation of Flux Concentration PM Machines: Study of the Influence of the Magnets Shape. International conference on electrical machines (ICEM 2012), Sep 2012, Marseille, France. 7 p., 10.1109/ICElMach.2012.6350276 . hal-00834006

\section{HAL Id: hal-00834006 https://hal.science/hal-00834006}

Submitted on 13 Jun 2013

HAL is a multi-disciplinary open access archive for the deposit and dissemination of scientific research documents, whether they are published or not. The documents may come from teaching and research institutions in France or abroad, or from public or private research centers.
L'archive ouverte pluridisciplinaire HAL, est destinée au dépôt et à la diffusion de documents scientifiques de niveau recherche, publiés ou non, émanant des établissements d'enseignement et de recherche français ou étrangers, des laboratoires publics ou privés. 


\title{
Analytical Computation of Flux Concentration PM Machines: Study of the Influence of the Magnets Shape
}

\author{
L. Belguerras, L. Hadjout, T. Lubin, S. Mezani, A. Rezzoug
}

\begin{abstract}
An exact 2-dimensional analytical method for calculating the magnetic field distribution in a Flux Concentration Permanent Magnet Machines (FCPMM) with sector magnets is developed and validated. The ability of the model to determine the performances of rectangular magnets FCPMM is then analyzed. A parametric study showed that the analytical model can predict the torque with a reasonable precision. Hence, this model can usefully be used for optimization purposes where savings in computation time are needed.
\end{abstract}

Index Terms-- Analytical solution, flux concentration, permanent magnet machines.

\section{INTRODUCTION}

$\mathrm{R}$ ecently, technology to generate a strong magnetic field have been the subject of considerable research $[1,2]$. In order to develop a higher magnetic flux density in the air gap, a flux concentration concept is one of the effective solutions. In these applications, the machine produces more torque compared to the rotor with surface mounted PMs [1].

Analytical techniques have been widely developed to calculate the magnetic field distribution in permanent magnet machines. In most of these techniques, Maxwell's equations are solved by separation of variables in low permeability sub-domains (air regions, magnets, windings) $[3,4,5,6]$. In particular, flux concentration switched PM machines have been studied in [7].

For cylindrical structures, polar coordinates are used. The geometry consists then of radial and circumferential edges. In order to consider rectangular shapes for example, multislice models can be introduced. This leads to more complicated interface conditions and an excessive growth of the computation time (because of the multiplication of the number of sub-domains). Another solution consists of using conformal mapping to handle the non radial sides of slot domains [8].

This study focuses on the ability of an analytical model, developed for sector magnets FCPMM, to predict the performances of rectangular magnets FCPMM. The magnets in both machines are considered to have the same volume.

L. Belguerras and L. Hadjout are with LSEI Laboratory, Université des Sciences et de la Technologie Houari Boumediene, BP 32, El-Alia, Bab-Ezzouar, Algiers, Algeria. (e-mail: lamia belguerras@yahoo.fr).

S. Mezani, T. Lubin and A. Rezzoug are with GREEN Laboratory, Université de Lorraine, Faculté des Sciences et Technologies, BP 70239, 54506, Vandoeuvre-lès-Nancy, France. (e-mail: smail.mezani@univlorraine.fr).
The first part of the paper introduces the sector PMs FCPMM and the analytical calculation of the magnetic field by the technique of separation of variables. The analytical computations are corroborated through finite element validations.

In the second part, we will analyze the capability of the developed analytical model in predicting rectangular magnets FCPMM performances. For this purpose, the rectangular magnets are replaced by sector ones having the same volume so the analytical computation can be done. A discussion on the obtained results terminates the paper.

\section{MACHINE DESCRIPTION}

In our studied configuration referred as Flux Concentration Permanent Magnets Machine (FCPMM), the rotor consists of different pieces of iron and sector magnets that are fixed jointly on a non-ferromagnetic shaft. The direction of magnetization is reversed from one magnet to the next. Schematic representation of the FCPMM is shown in Fig. 1.

The geometrical parameters of prototype FCPMM to be investigated are the inner radius of the rotor yoke $R_{l}$, the radius of the rotor surface $R_{2}$ and the stator bore radius $R_{3}$.

The rotor consists of $2 p$ ( $p$ is the number of pole-pairs) sector PMs. The angular position of the $i$-th PM is defined (Fig. 1) by

$\theta_{i}=-\frac{\beta}{2}+\frac{i \pi}{p}+\theta_{0} \quad$ with $\quad 1 \leq i \leq 2 p$

where $\theta_{0}$ is the initial angular position of the rotor and $\beta$ the PM opening angle.

\section{PROBLEM FORMULATION AND ASSUMPTIONS}

In developing the $2 \mathrm{D}$ analytical model, a magnetic vector potential formulation is used in polar coordinates. The relative permeability is considered infinite for the iron parts and is equal to 1 for the PMs.

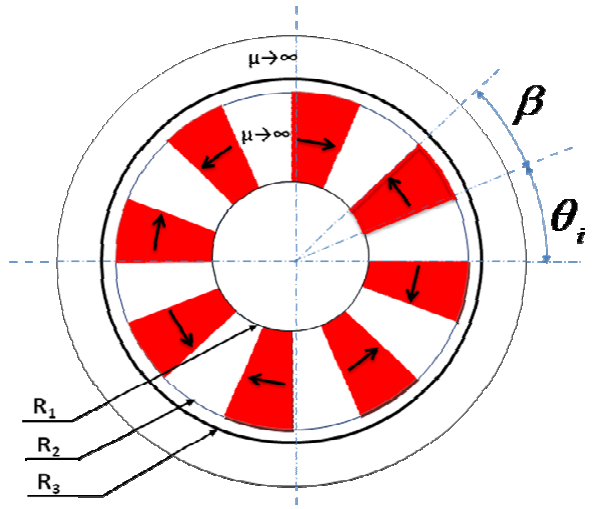

Fig. 1. Geometry of the studied machine 


\section{A. Source Terms}

The permanent magnets buried into the rotor of the machine are tangentially magnetized. Each magnet is magnetized in a reverse direction of its neighboring ones (Fig.1). Hence, the magnetization vector of the $i^{\text {th }}$ permanent magnet regions is

$$
\vec{M}=(-1)^{i} \frac{B_{r}}{\mu_{0}} \vec{e}_{\theta}
$$

where $B_{r}$ is the remanent flux density of the magnet.

The stator winding is represented by a current sheet distributed over the stator bore radius $\left(\mathrm{r}=R_{3}\right)$. Only the fundamental component is considered in this study.

$$
\vec{K}(\theta)=K_{m} \cos (p(\theta-\alpha)) \cdot \vec{e}_{z}
$$

where $K_{m}, \alpha, p, \vec{e}_{z}$ are respectively the peak value of the current sheet in $(\mathrm{A} / \mathrm{m})$, the angular position of the current sheet, the number of pole pairs and the unit vector along the $\mathrm{z}$ axis.

\section{B. Analytical expressions of the magnetic field in different subdomains}

The studied structure is divided into a shaft (domain I), an air-gap (domain II) and a permanent magnet region (domain $i$ ) (Fig. 2).

In order to simplify the theoretical analysis in the different sub-domains, we adopt the following notations

$$
\begin{aligned}
& P_{z}(a, b)=\left(\frac{a}{b}\right)^{z}+\left(\frac{b}{a}\right)^{z} \\
& E_{z}(a, b)=\left(\frac{a}{b}\right)^{z}-\left(\frac{b}{a}\right)^{z}
\end{aligned}
$$

In polar coordinates, the Poisson's equation in the i-th permanent magnet sub-domain region is

$$
\Delta A_{i}=-(-1)^{i} \frac{B_{r}}{r}
$$

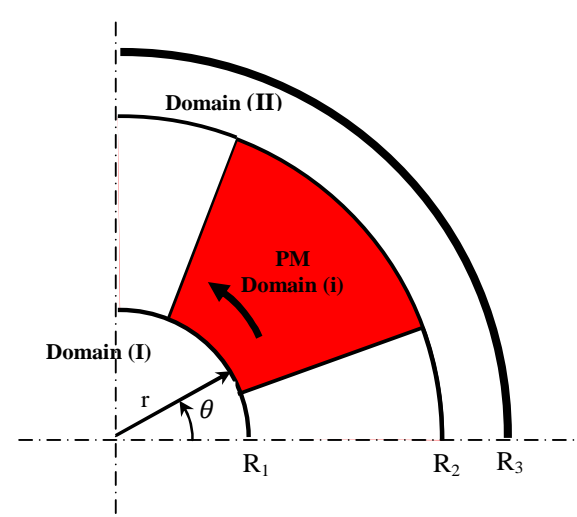

Fig. 2. Studied sub-domains

For the shaft (sub-domain I) and the air-gap (sub-domain II), Laplace's equation applies

$$
\begin{aligned}
& \Delta A_{I}=0 \\
& \Delta A_{I I}=0
\end{aligned}
$$

\section{Boundary conditions}

The boundary conditions for the $i$-th PM domain are

$\left.\frac{\partial A_{i}}{\partial \theta}\right|_{\theta=\theta_{i}}=0$ and $\left.\frac{\partial A_{i}}{\partial \theta}\right|_{\theta=\theta_{i}+\beta}=0$

The continuity conditions between the $i$-th PM and subdomains I, II are

$$
\begin{aligned}
& A_{i}\left(R_{1}, \theta\right)=A_{I}\left(R_{1}, \theta\right) \\
& A_{i}\left(R_{2}, \theta\right)=A_{I I}\left(R_{2}, \theta\right)
\end{aligned}
$$

The continuity of the tangential magnetic field at the interface between the permanent magnet and the shaft, can be written as

$$
\left.\frac{\partial A_{I}}{\partial r}\right|_{r=R_{1}}=f(\theta)
$$

With $f(\theta)= \begin{cases}\left.\frac{\partial A_{i}}{\partial r}\right|_{\mathrm{r}=\mathrm{R}_{1}}+(-1)^{i} B_{\mathrm{r}} \quad \text { if } \theta \in\left[\theta_{\mathrm{i}}, \theta_{i}+\beta\right] \\ 0 \quad \text { elsewhere }\end{cases}$

The continuity of the tangential magnetic field at the interface between the permanent magnet and the air gap can be written as

$$
\left.\frac{\partial A_{I I}}{\partial r}\right|_{r=R_{2}}=g(\theta)
$$

with $g(\theta)=\left\{\begin{array}{lc}\left.\frac{\partial A_{i}}{\partial r}\right|_{\mathrm{r}=\mathrm{R}_{2}}+(-1)^{i} B_{\mathrm{r}} \text { if } \theta \in\left[\theta_{\mathrm{i}}, \theta_{i}+\beta\right] \\ 0 \quad \text { elsewhere }\end{array}\right.$

On the stator bore $\left(r=R_{3}\right)$, the boundary condition is

$$
\left.\frac{\partial A_{I I}}{\partial r}\right|_{r=R_{3}}=\mu_{0} K(\theta)
$$

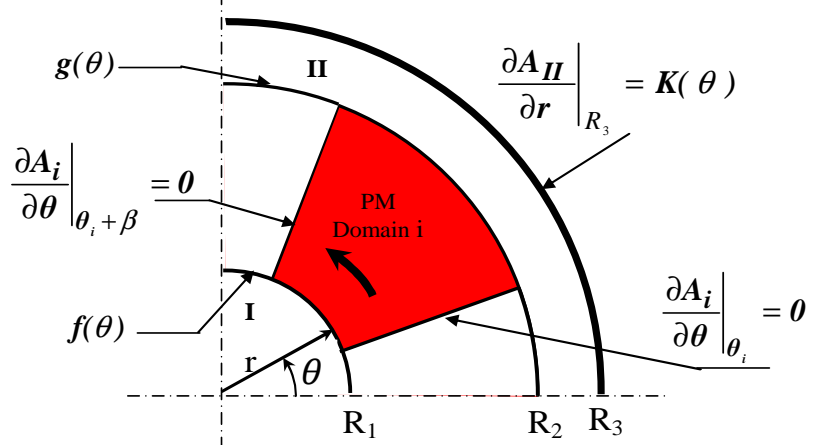

Fig. 3. Boundary conditions

\section{ANALYTICAL SOLUTION}

For solving the partial differential equations, the method of separation of variables is used in cylindrical coordinates. 
A. General Solution of Poisson's equation in the i-th PMs sub-domain (region i)

In the $\mathrm{i}^{\text {th }} \mathrm{PM}$ sub-domain, the problem to solve is

$$
\frac{\partial^{2} A_{i}}{\partial r^{2}}+\frac{1}{r} \frac{\partial A_{i}}{\partial r}+\frac{1}{r^{2}} \frac{\partial^{2} A_{i}}{\partial \theta^{2}}=-(-1)^{i} \frac{B_{r}}{r}\left\{\begin{array}{l}
R_{1} \leq r \leq R_{2} \\
\theta_{i} \leq \theta \leq \theta_{i}+\beta
\end{array}\right.
$$

The general solution of (17) can be written as

$$
\begin{aligned}
& A_{i}(r, \theta)=-r(-1)^{i} B_{r}+A_{0}^{i}+B_{0}^{i} \ln r \\
& +\sum_{k=1}^{\infty}\left(A_{k}^{i} \frac{E_{k \pi / \beta}\left(r, R_{2}\right)}{E_{k \pi / \beta}\left(R_{1}, R_{2}\right)}-B_{k}^{i} \frac{E_{k \pi / \beta}\left(r, R_{1}\right)}{E_{k \pi / \beta}\left(R_{1}, R_{2}\right)}\right) \cdot \cos \left(\frac{k \pi}{\beta}\left(\theta-\theta_{i}\right)\right.
\end{aligned}
$$

where $\mathrm{k}$ is a positive integer, $\mathrm{E}_{k \pi / \beta}\left(r, R_{2}\right)$ is given by (5).

The constants $A_{0}^{i}, B_{0}^{i}, A_{k}^{i}$ and $B_{k}^{i}$ are determined using a Fourier series expansion of shaft and air-gap magnetic vector potentials $A_{I}\left(R_{1}, \theta\right)$ and $A_{I I}\left(R_{2}, \theta\right)$ over the PMs region interval $\left[\theta_{i}, \theta_{i}+\beta\right]$. They are given by

$$
\begin{aligned}
& A_{0}^{i}+B_{0}^{i} \ln R_{1}=\frac{1}{\beta} \int_{\theta_{i}}^{\theta_{i}+\beta}\left(R_{1}(-1)^{i} B_{r}+A_{I}\left(R_{1}, \theta\right)\right) d \theta \\
& A_{0}^{i}+B_{0}^{i} \ln R_{2}=\frac{1}{\beta} \int_{\theta_{i}}^{\theta_{i}+\beta}\left(R_{2}(-1)^{i} B_{r}+A_{I I}\left(R_{2}, \theta\right)\right) d \theta \\
& A_{k}^{i}=\frac{2}{\beta} \int_{\theta_{i}}^{\theta_{i}+\beta}\left(R_{1}(-1)^{i} B_{r}+A_{I}\left(R_{1}, \theta\right)\right) \cos \left(\frac{k \pi}{\beta}\left(\theta-\theta_{i}\right)\right) d \theta \\
& B_{k}^{i}=\frac{2}{\beta} \int_{\theta_{i}}^{\theta_{i}+\beta}\left(R_{2}(-1)^{i} B_{r}+A_{I I}\left(R_{2}, \theta\right)\right) \cos \left(\frac{k \pi}{\beta}\left(\theta-\theta_{i}\right)\right) d \theta
\end{aligned}
$$

B. General solution of Laplace's equation in the shaft (sub-domain I)

The shaft sub-domain and its associated boundary conditions are shown in Fig. 3. The problem to solve is

$\frac{\partial^{2} A_{I}}{\partial r^{2}}+\frac{1}{r} \frac{\partial A_{I}}{\partial r}+\frac{1}{r^{2}} \frac{\partial^{2} A_{I}}{\partial \theta^{2}}=0 \quad$ for $\left\{\begin{array}{l}0 \leq r \leq R_{1} \\ 0 \leq \theta \leq 2 \pi\end{array}\right.$

By taking into account the boundary conditions (12) and (13), the general solution of the magnetic vector potential in the shaft can be written as

$$
A_{I}(r, \theta)=\sum_{m=1}^{\infty} \frac{R_{1}}{m}\left(\frac{r}{R_{1}}\right)^{m}\left(A_{m}^{I} \cos (m \theta)+B_{m}^{I} \sin (m \theta)\right)
$$

Where $m$ is a positive integer in the shaft domain, the coefficients $A_{m}^{I}$ and $B_{m}^{I}$ are determined by using a Fourier series expansions of $f(\theta)$ over the interval $[0,2 \pi]$.
$A_{m}^{I}=\frac{2}{2 \pi} \int_{0}^{2 \pi} f(\theta) \cdot \cos (m \theta) \cdot d \theta$

$B_{m}^{I}=\frac{2}{2 \pi} \int_{0}^{2 \pi} f(\theta) \cdot \sin (m \theta) \cdot d \theta$

C. General solution of Laplace's equation in the air-gap (sub-domain II)

The air-gap sub-domain and its associated boundary conditions are shown in Fig. 3. The problem to solve is

$\frac{\partial^{2} A_{I I}}{\partial r^{2}}+\frac{1}{r} \frac{\partial A_{I I}}{\partial r}+\frac{1}{r^{2}} \frac{\partial^{2} A_{I I}}{\partial \theta^{2}}=0$ for $\left\{\begin{array}{l}R_{2} \leq r \leq R_{3} \\ 0 \leq \theta \leq 2 \pi\end{array}\right.$

By taking into account the boundary conditions (14) and (15), the general solution of the magnetic vector potential in the air-gap sub-domain can be written as

$$
\begin{aligned}
& A_{I I}(r, \theta)= \\
& +\sum_{n=1}^{\infty}\left(A_{n}^{I I} \frac{R_{2}}{n} \frac{\mathrm{P}_{n}\left(r, R_{3}\right)}{\mathrm{E}_{n}\left(R_{2}, R_{3}\right)}+B_{n}^{I I} \frac{R_{3}}{n} \frac{\mathrm{P}_{n}\left(r, R_{2}\right)}{\mathrm{E}_{n}\left(R_{3}, R_{2}\right)}\right) \cos (n \theta) \\
& +\sum_{n=1}^{\infty}\left(C_{n}^{I I} \frac{R_{2}}{n} \frac{\mathrm{P}_{n}\left(r, R_{3}\right)}{\mathrm{E}_{n}\left(R_{2}, R_{3}\right)}+D_{n}^{I I} \frac{R_{2}}{n} \frac{\mathrm{P}_{n}\left(r, R_{2}\right)}{\mathrm{E}_{n}\left(R_{3}, R_{2}\right)}\right) \sin (n \theta)
\end{aligned}
$$

where $n$ is a positive integer, $\mathrm{P}_{n}\left(r, R_{2}\right)$ and $\mathrm{E}_{n}\left(r, R_{3}\right)$ are defined by (4) and (5). The coefficients $A_{n}^{I I}, B_{n}^{I I}, C_{n}^{I I}$ and $D_{n}^{I I}$ are determined using a Fourier series expansions of $K(\theta)$ and $g(\theta)$ over the air-gap interval $[0,2 \pi]$

$A_{n}^{I I}=\frac{2}{2 \pi} \int_{0}^{2 \pi} g(\theta) \cdot \cos (n \theta) \cdot d \theta$

$B_{n}^{I I}=\frac{2}{2 \pi} \int_{0}^{2 \pi} \mu_{0} K(\theta) \cdot \cos (n \theta) \cdot d \theta$

$C_{n}^{I I}=\frac{2}{2 \pi} \int_{0}^{2 \pi} g(\theta) \cdot \sin (n \theta) \cdot d \theta$

$D_{n}^{I I}=\frac{2}{2 \pi} \int_{0}^{2 \pi} \mu_{0} K(\theta) \cdot \sin (n \theta) \cdot d \theta$

The magnetic flux density components are

$B_{I I r}=\frac{1}{r} \frac{\partial A_{I I}}{\partial \theta}$
$B_{I I \theta}=-\frac{\partial A_{I I}}{\partial r}$

\section{Electromagnetic torque}

The electromagnetic torque is obtained using the Maxwell stress tensor. A circle of radius $R_{e}$ in the air-gap is taken as the integration path so the electromagnetic torque is expressed as follows 
$T_{e}=\frac{L R_{e}^{2}}{\mu_{0}} \int_{0}^{2 \pi} B_{I I r}\left(R_{e}, \theta\right) \cdot B_{I I \theta}\left(R_{e}, \theta\right) \cdot d \theta$

where $L$ is the axial length of the FCPMM.

According to (33) and (34), the analytical expression for the electromagnetic torque becomes

$$
T_{e}=\frac{\pi L R_{e}^{2}}{\mu_{0}} \sum_{n=1}^{\infty}\left(W_{n} X_{n}+Y_{n} Z_{n}\right)
$$

where

$$
\begin{gathered}
W_{n}=-A_{n}^{I I} \frac{R_{2}}{R_{e}} \frac{\mathrm{P}_{n}\left(R_{e}, R_{3}\right)}{\mathrm{E}_{n}\left(R_{2}, R_{3}\right)}-B_{n}^{I I} \frac{R_{3}}{R_{e}} \frac{\mathrm{P}_{n}\left(R_{e}, R_{2}\right)}{\mathrm{E}_{n}\left(R_{3}, R_{2}\right)} \\
X_{n}=-C_{n}^{I I} \frac{R_{2}}{R_{e}} \frac{\mathrm{E}_{n}\left(R_{e}, R_{3}\right)}{\mathrm{E}_{n}\left(R_{2}, R_{3}\right)}-D_{n}^{I I} \frac{R_{3}}{R_{e}} \frac{\mathrm{E}_{n}\left(R_{e}, R_{2}\right)}{\mathrm{E}_{n}\left(R_{3}, R_{2}\right)} \\
Y_{n}=C_{n}^{I I} \frac{R_{2}}{R_{e}} \frac{\mathrm{P}_{n}\left(R_{e}, R_{3}\right)}{\mathrm{E}_{n}\left(R_{2}, R_{3}\right)}+D_{n}^{I I} \frac{R_{3}}{R_{e}} \frac{\mathrm{P}_{n}\left(R_{e}, R_{2}\right)}{\mathrm{E}_{n}\left(R_{3}, R_{2}\right)} \\
Z_{n}=-A_{n}^{I I} \frac{R_{2}}{R_{e}} \frac{\mathrm{E}_{n}\left(R_{e}, R_{3}\right)}{\mathrm{E}_{n}\left(R_{2}, R_{3}\right)}-B_{n}^{I I} \frac{R_{3}}{R_{e}} \frac{\mathrm{E}_{n}\left(R_{e}, R_{2}\right)}{\mathrm{E}_{n}\left(R_{3}, R_{2}\right)}
\end{gathered}
$$

\section{VALIDATION OF THE ANALYTICAL MODEL}

In order to validate the proposed model, the analytical results have been compared with 2-D finite-element simulations obtained using FEM software [9]. The geometrical parameters given in Table I are considered in the simulation studies.

Fig.4 shows the magnetic flux lines under no-load conditions $\left(\mathrm{K}_{\mathrm{m}}=0\right)$ and at full-load $\left(\mathrm{K}_{\mathrm{m}} \neq 0\right)$. It has to be noticed that the pull-out torque is obtained for a current sheet angle $\alpha \approx \pi / 8$ since the reluctance torque is negligible. The flux lines at no-load are symmetrical but it's not anymore the case at full-load because of the presence of the current sheet. The figures also show a relatively high leakage flux in the shaft.

The waveforms of the flux density distribution (radial and tangential components) in the middle of the air-gap are plotted in Fig. 5 and Fig. 6. The armature magnetic field due to the current sheet distorts both the radial and tangential flux densities obtained at no-load.

The static torque versus angular position of the current sheet $\alpha$ (in electrical degrees) is presented in Fig.7. The torque waveform is sinusoidal. As expected, the pull-out torque is obtained for a load angle practically equals to $\pi / 2$ electrical angle (viz. $\alpha \approx \pi / 8$ ).

A very good agreement is noticed between the finite element predictions and the analytical results.

\section{VALIDITY OF THE ANALYTICAL MODEL FOR THE COMPUTATION OF FCPMM WITH RECTANGULAR PMS}

The rotor of FCPMM usually uses rectangular magnets instead of sector ones. The developed analytical model is only valid for sector type permanent magnets which only contain radial and circumferential edges.
It is possible to divide the rectangular magnet into a finite number of radial slices and use the analytical model to calculate the magnetic field distribution. However, this will drastically increases the number of sub-domains and penalizes the computation time.

In this section, we will analyze the capability of the developed analytical model in predicting rectangular magnets FCPMM performances. For this purpose, the

\begin{tabular}{|c|c|c|}
\hline Symbol & Quantity & value \\
\hline $\mathrm{R}_{1}$ & Inner radius of the rotor & $10 \mathrm{~mm}$ \\
\hline$R_{2}$ & Outer radius of the rotor & $50 \mathrm{~mm}$ \\
\hline $\mathrm{p}$ & Number of pole pairs & 4 \\
\hline $\mathrm{R}_{3}$ & Inner radius of the stator & $52 \mathrm{~mm}$ \\
\hline$\beta$ & PM opening angle & $0.3 \pi / \mathrm{p} \mathrm{rad}$ \\
\hline $\mathrm{L}$ & Axial length & $100 \mathrm{~mm}$ \\
\hline M & $\begin{array}{l}\text { Number of harmonics used for } \\
\text { magnetic field calculation in the } \\
\text { shaft domain }\end{array}$ & 50 \\
\hline $\mathrm{N}$ & $\begin{array}{l}\text { Number of harmonics used for } \\
\text { magnetic field calculation in the } \\
\text { air-gap domain }\end{array}$ & 50 \\
\hline $\mathrm{K}$ & $\begin{array}{l}\text { Number of harmonics used for } \\
\text { magnetic field calculation in the } \\
\text { PM domain }\end{array}$ & 50 \\
\hline $\mathrm{K}_{\mathrm{m}}$ & Peak value of the current sheet & $500 \mathrm{~A} / \mathrm{cm}$ \\
\hline $\mathrm{B}_{\mathrm{r}}$ & Remanence of the PM & $1.2 \mathrm{~T}$ \\
\hline
\end{tabular}
rectangular magnets are replaced by sector ones having the same volume so the analytical computation can be done.

TABLE I

GEOMETRICAL PARAMETERS OF FCPMM WITH SECTOR PMS

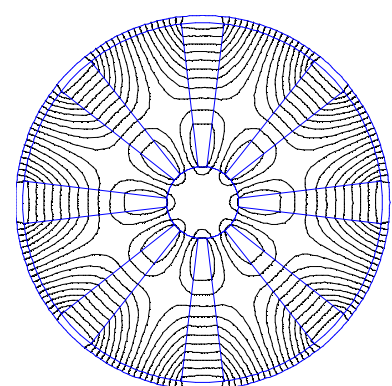

(a)

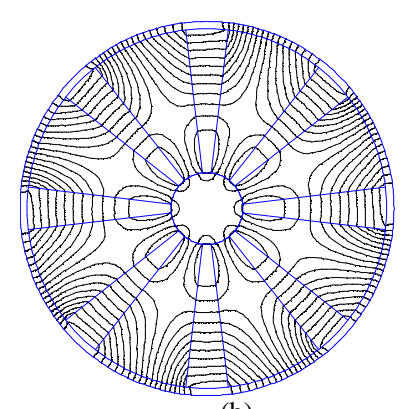

(b)
Fig. 4. Magnetic flux lines under (a) no-load and (b) full-load conditions

While replacing the rectangular magnet, having arc edges at $R_{1}$ and $R_{2}$, by the sector one, there is a feasibility limit concerning the rectangular PM width (which corresponds to the chord of the arc edge). Indeed, this length couldn't exceed $R_{1} \times \pi / p$ (pole-pitch length).

In practice, this last choice is generally adopted so the iron pieces (between magnets) are nearly triangular. Furthermore, the leakage flux through the shaft will be reduced as it can be seen later.

The sector PM has then an angular opening

$$
\beta=\frac{\pi}{\mathrm{p}} \frac{\mathrm{R}_{1}}{\mathrm{R}_{\mathrm{av}}}
$$

where $\mathrm{R}_{\mathrm{av}}=\left(\mathrm{R}_{1}+\mathrm{R}_{2}\right) / 2$ is the mean radius of the PM.

In what follows, the rectangular and sector PMs FCPMM are respectively calculated by FEM and using the analytical model. 


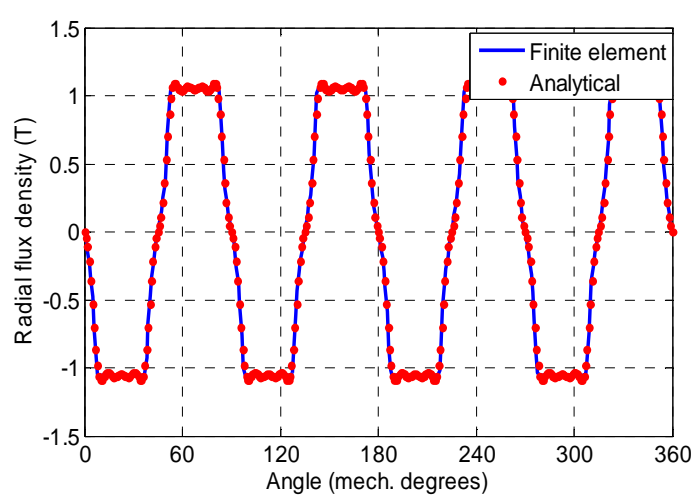

(a)

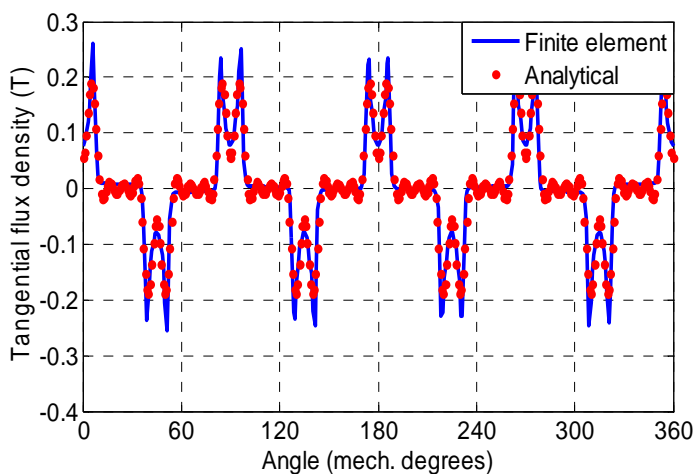

(b)

Fig. 5. Radial (a) and tangential (b) flux densities in the middle of the air gap under no-load conditions $\left(\mathrm{K}_{\mathrm{m}}=0\right)$

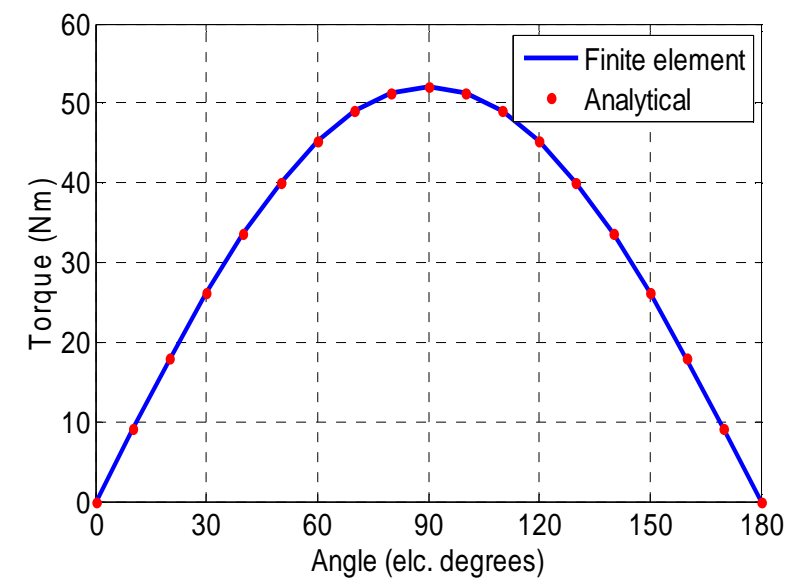

Fig. 7. Static torque of FCPMM with sector PMs

\section{A. Magnetic flux density distribution}

Let's define the ratio between $R_{1}$ and $R_{2}$ as

$\alpha_{r}=\frac{R_{1}}{R_{2}}$

For $\mathrm{p}=6$ and $\alpha_{r}=0.4$ (the other dimensions are those given in Table I), Fig.8 shows the magnetic flux lines for a FCPMM with sector and rectangular shape PMs under no load conditions. It can be seen that with the sector PMs, a large portion of magnetic flux lines from the magnets is lost through the shaft. Of course, the FCPMM with rectangular magnets doesn't offer a flux path toward the shaft which results in low leakage flux.

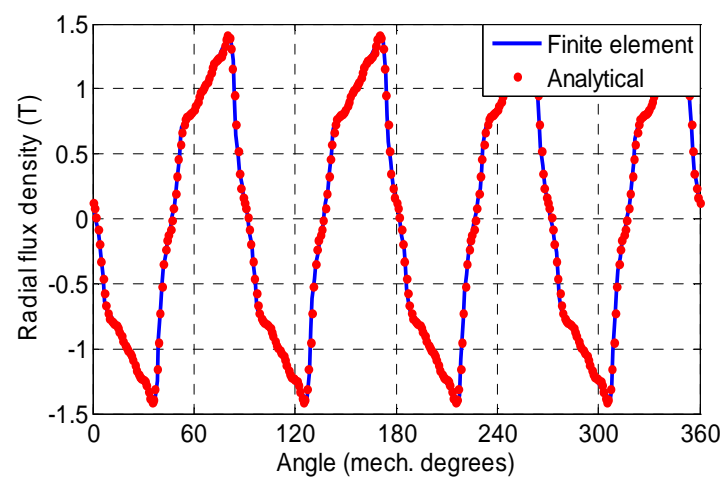

(a)

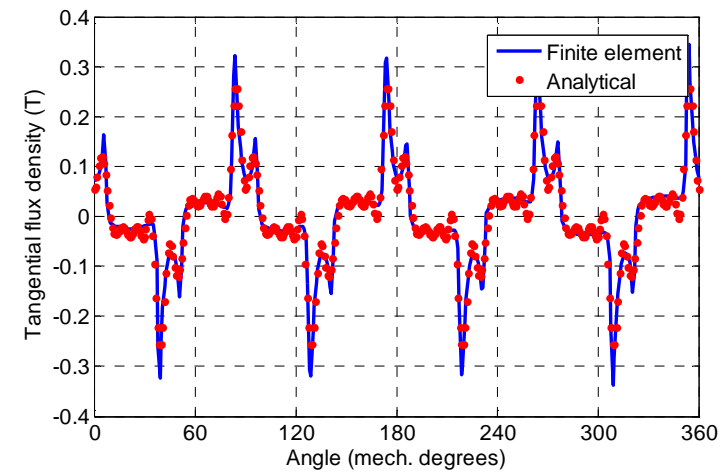

(b)

Fig. 6. Radial (a) and tangential (b) flux densities in the middle of the air gap under full-load conditions $\left(\mathrm{K}_{\mathrm{m}} \neq 0, \alpha=\pi / 8\right)$

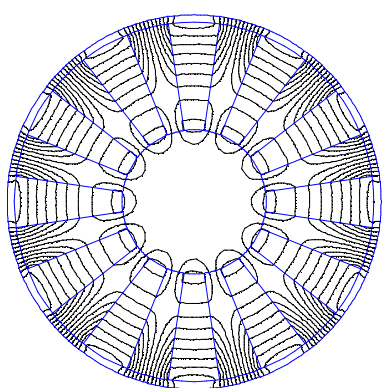

(a)

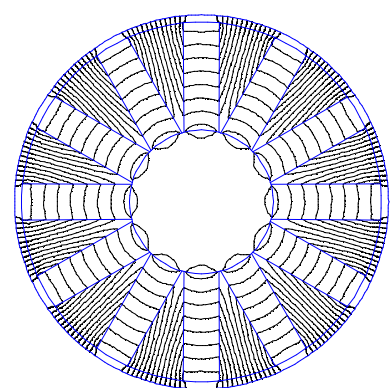

(b)
Fig. 8.Magnetic flux lines of FCPMM with (a) sector and (b) rectangular PMs under no-load conditions ( $\mathrm{p}=6$ and $\alpha_{\mathrm{r}}=0.4$ )

In Fig.9 the radial flux density waveforms in the middle of the air gap of FCPMM with rectangular and sector PMs are presented. It can be seen that the two curves are nearly the same. The harmonic spectra show that the difference between the fundamental components is about $10 \%$.

Obviously, this comparison has to be deeply analyzed through a parametric study. Here, we have fixed the stator bore radius $R_{3}$ and the rotor radius $R_{2}$ (the air-gap is kept constant) to their values given in Table I. Then, only the number of pole-pairs $p$ and the ratio $\alpha_{r}=R_{1} / R_{2}$ vary.

\section{B. Influence of the magnets height on the pull-out torque}

Fig.10 shows the pull-out torque variation versus different values of $\alpha_{r}$ for $\mathrm{p}=3$ and $\mathrm{p}=6$. It can be seen that both the curves obtained analytically and numerically have the same tendency. It can be noticed that the torque values obtained analytically are closer to the ones predicted by FEM as $\alpha_{r}$ increases. Notice that the increase of $\alpha_{r}$ (typically 
for $\left.\alpha_{\mathrm{r}}>0.7\right)$ results in lower iron surface which leads to a high saturation level. This is an important issue but it is outside the aim of this paper.

The maximum values of the torque are located in the interval $\alpha_{\mathrm{r}}=0.4 \div 0.5$ for $\mathrm{p}=6$ and in the interval $\alpha_{\mathrm{r}}=0.3 \div 0.5$ for $p=3$. The pull-out torque calculated by FEM is about $74 \mathrm{Nm}$ for $\mathrm{p}=6$ and about $66 \mathrm{Nm}$ for $\mathrm{p}=3$. These values are about $10 \%$ higher than the ones obtained analytically. This difference is probably caused by the higher leakage flux through the shaft of the equivalent sector PMs FCPMM.

\section{Influence of the number of pole-pairs on the pull-out torque}

Fig.11 shows the pull-out torque versus the number of pole-pairs for $\alpha_{\mathrm{r}}=0.1$ and $\alpha_{\mathrm{r}}=0.4$.

Again, it can be seen that the two curves have the same tendency and the torque values obtained analytically are, in the worst case, $10 \%$ lower than the ones calculated by FEM.

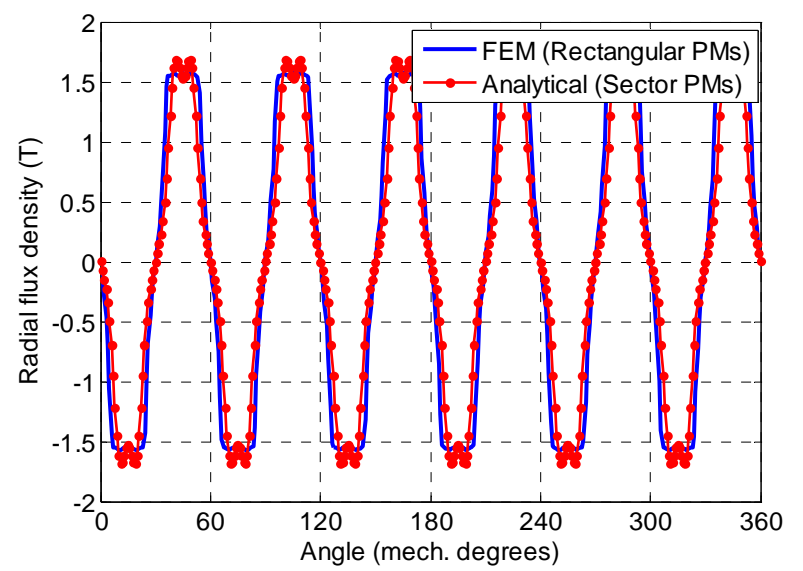

(a)

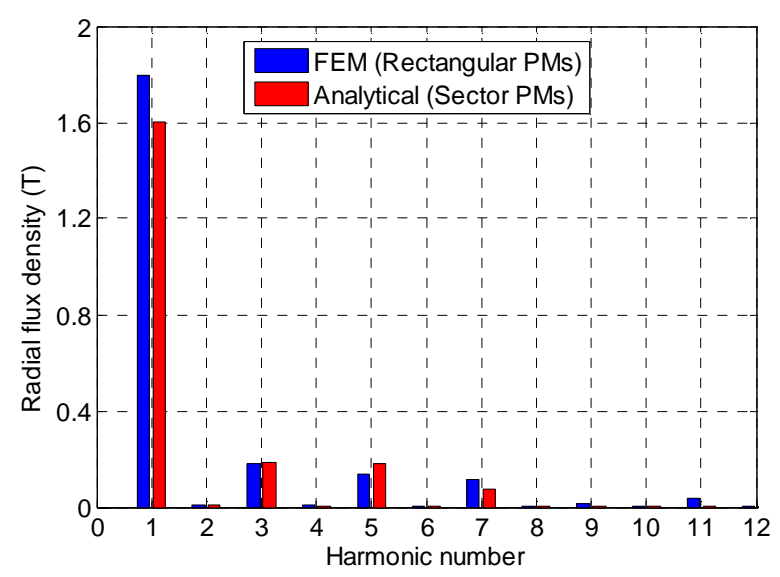

(b)

Fig. 9. Radial flux density waveforms (a) and their harmonic spectra (b) at no-load $\left(\mathrm{K}_{\mathrm{m}}=0\right)$

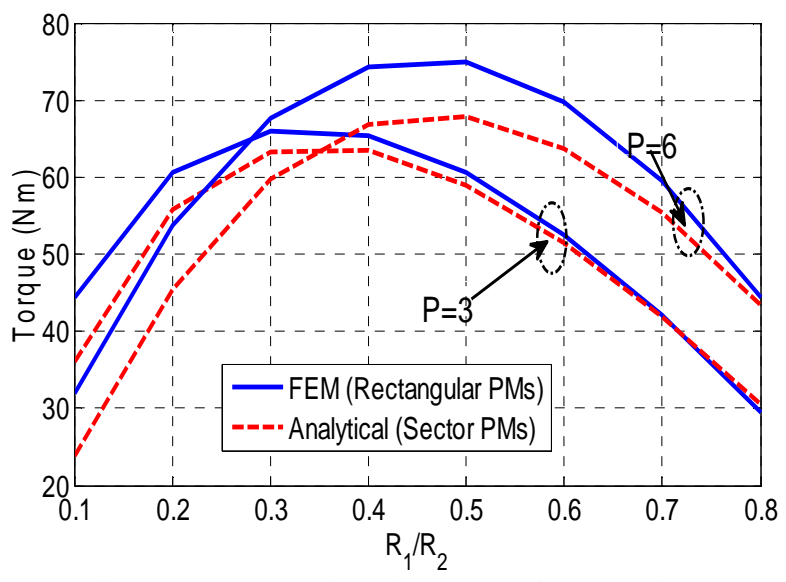

Fig. 10. Pull-out torque versus the ratio $\alpha_{r}=R_{1} / R_{2}$ for $p=3$ and $p=6$.

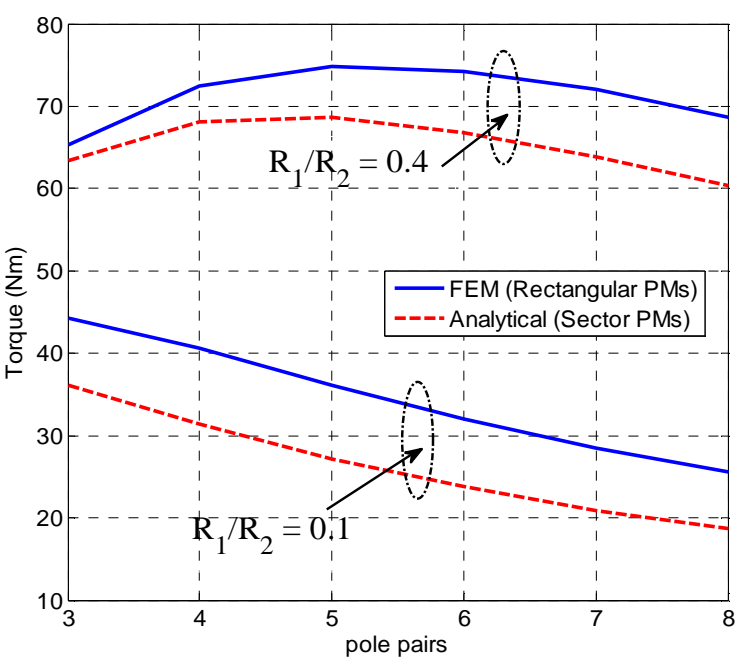

Fig.11. Pull-out torque vs. the number of pole-pairs for $\alpha_{\mathrm{r}}=0.1$ and $\alpha_{\mathrm{r}}=0.4$

\section{Torque optimization}

In order to determine the most suitable configuration in terms of torque production of the FCPMM, Fig.12 shows the contour plots representing the pull-out torque as a function of the number of pole-pairs $\mathrm{p}$ and the ratio $\alpha_{\mathrm{r}}=\mathrm{R}_{1} / \mathrm{R}_{2}$.

It can be seen that the analytical and the numerical computations follow the same trend. This is an important result since the analytical model is suitable in the determination of the optimum values of $p$ and $\alpha_{r}$ that maximise the torque when the other geometrical parameters are fixed. Of course, this is of great benefit in any optimisation study since the analytical computation is very quick.

Concerning the quantitative results, the maximum value of the torque calculated by the analytical model is about $67 \mathrm{Nm}$ and is located in the intervals $\mathrm{p}=4 \div 7$ and $\alpha_{\mathrm{r}}=0.38 \div 0.54$. The numerical computations give a maximum torque value of about $74 \mathrm{Nm}$ located in the same intervals as the analytical predictions viz. $\mathrm{p}=4 \div 6$ and $\alpha_{\mathrm{r}}=0.38 \div 0.54$. 


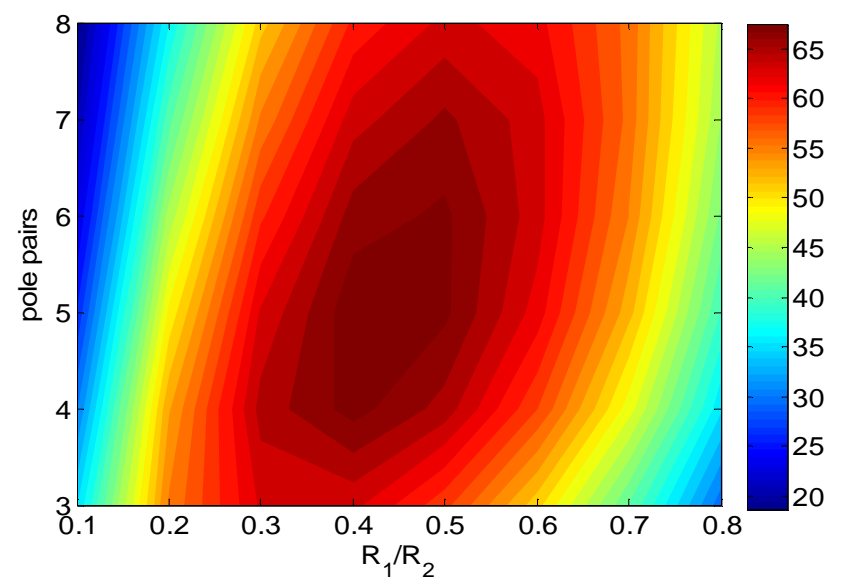

(a)

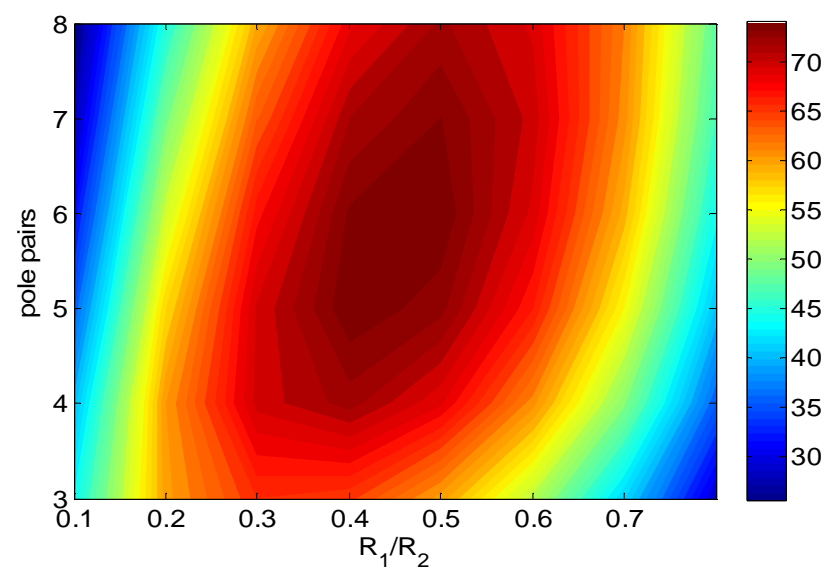

(b)

Fig. 12.Contour plots of the pull-out torque of FCPMM as a function of the number of pole-pairs $p$ and the ratio $\alpha_{r}=R_{1} / R_{2}$

(a) Analytical (sector PMs) (b) FEM (rectangular PMs)

\section{CONCLUSION}

In this work, we have developed a 2D model based on an exact analytical resolution of the magnetic field distribution in each sub domain for FCPMM with sector PMs. This model has been validated by finite element computations.

An important part of the study has been devoted to analyze the capability of the analytical model in evaluating the performances of rectangular PMs FCPMM. For this purpose, the rectangular magnets are replaced by sector ones having the same volume so the analytical computation can be done. The different computations showed that the analytical model predicts the value of the pull-out torque within a maximum error of about $10 \%$ when compared to the finite element calculations. Furthermore, it has been shown that the analytical and the numerical computations follow the same trend. This is of great benefit in any parametric or optimisation study where quick models are needed.

\section{REFERENCES}

[1] M. Enokizono, T. Todaka, Y. Tsuchida, A. Ikariga, S. Urata, T. Mauchi, A. Umeduki, K. Ebihara, H. Shioduki, H. Shimoji, Y. Gotho, M. Obata, Y. Kido, "Development of high density and high efficiency machines," Journal of Materials Processing Technology, Vol.181, No.1-3, pp.110-114, 2007.
[2] A. Ikariga, H. Shimoji, T. Todaka and M. Enokizono, "High-Density Permanent Magnet Machines," Proc. of ISEM, pp.112-113, 2005.

[3] Z. J. Liu and J. T. Li, "Analytical solution of air-gap field in permanent magnet motors taking into account the effect of pole transition over slots," IEEE Trans. Magn., vol. 43, no. 10, pp. 3872 3882, Oct. 2007

[4]Z. Q. Zhu, L. J. Wu, and Z. P. Xia, "An accurate subdomain model for magnetic field computation in slotted surface-mounted permanent magnet machines," IEEE Trans. Magn., vol. 46, no. 4, pp. 11001115, Apr. 2010.

[5] Q. Gu and H. Gao, "Effect of slotting in PM electrical machines," Elect. Mach. Power Syst., vol. 10, pp. 273-284, 1985.

[6] T. Lubin, S. Mezani, and A. Rezzoug, "Exact analytical method for magnetic field computation in the air-gap of cylindrical electrical machines considering slotting effects, " IEEE Trans. Magn., vol. 46, no. 4, pp. 1092-1099, Apr. 2010.

[7] B. L. J. Gysen, E. Ilhan, K. J. Meessen, J. J. H. Paulides, and E. A. Lomonova, "Modeling of Flux Switching Permanent Magnet Machines with Fourier Analysis," IEEE Trans. Magn., vol. 46, no. 6, pp. 1499-1502, Jun. 2010.

[8] L. J. Wu, Z. Q. Zhu, D. Staton, M. Popescu, and D. Hawkins, "Comparison of Analytical Models for Predicting Cogging Torque in Surface-Mounted PM Machines," Proc. ICEM, Rome, 6 p., 2010

[9]D. C. Meeker, Finite Element Method Magnetics Version 4.2 (1 October 2011 Build) http://www.femm.info

\section{BIOGRAPHIES}

Lamia Belguerras was born in Algiers, Algeria, in 1979. She received the Dipl.-Ing. and the Magister degrees from the University of Sciences and Technology Houari Boumediene (USTHB), Algiers, Algeria, in 2005 and 2008, respectively.

She is currently an assistant professor and a $\mathrm{PhD}$ student at "Laboratoire des Systèmes Electriques et Industriels", USTHB, Algiers, Algeria where her research interests include the modeling and optimization of electrical machines and superconducting magnetic couplings.

Larbi Hadjout was born in Bordj-Menaïel, Algeria, in 1967. He received the Dipl.-Ing., the Magister and the PhD degrees from Ecole Nationale Polytechnique, Algiers, Algeria in 1991, 1994 and 2006, respectively.

$\mathrm{He}$ is currently a Senior Lecturer at "Laboratoire des Systèmes Electriques et Industriels", USTHB, Algiers, Algeria where his research interests include the modeling and design of electrical machines.

Thierry Lubin was born in Sedan, France, in 1970. He received the M.S degree from the University Pierre et Marie Curie, Paris 6, France, in 1994, and the Ph.D. degree from the University Henri Poincaré, Nancy, France, in 2003 .

$\mathrm{He}$ is currently a Lecturer of Electrical Engineering at the Groupe de Recherche en Electrotechnique et Electronique de Nancy, University of Lorraine, Nancy. His research interests include modeling and control of electrical machines, and applied superconductivity in electrical devices.

Smail Mezani was born in Algiers, Algeria, in 1974. He received the Dipl.-Ing. and the Magister degrees from the University of Sciences and Technology Houari Boumediene, Algiers, Algeria, in 1996 and 1999 respectively, and the Ph.D. degree from the Institut National Polytechnique de Lorraine, Nancy, France, in 2004.

$\mathrm{He}$ is currently a Lecturer at the Groupe de Recherche en Electrotechnique et Electronique de Nancy, University of Lorraine, Nancy, France. His research interests include the applications of superconductors in electromechanical devices.

Abderrezak Rezzoug received the degree in electrical engineering from " Ecole Nationale Supérieure D'électricité et de Mécanique, Institut National Polytechnique de Lorraine (INPL), Nancy, France, in 1972, and the Dr. Ing. diploma and the Ph.D. degrees from INPL, in 1979 and 1987, respectively. Until 1991, he was an Assistant Professor at INPL.

$\mathrm{He}$ is currently a Professor of Electrical Engineering at the University of Lorraine, Nancy, where he is also a member of the Groupe de Recherche en Electrotechnique et Electronique de Nancy. His research interests include superconducting applications to electrical devices, and the control and diagnosis of electrical machines. 